\title{
Designing learning environments to promote academic literacy in mathematics in multilingual secondary mathematics classrooms
}

\author{
William Zahner $^{1}\left[\right.$ Ernesto Daniel Calleros $^{1} \cdot$ Kevin Pelaez $^{1}$
}

Accepted: 5 February 2021 / Published online: 26 February 2021

(c) The Author(s) 2021

\begin{abstract}
Emerging multilingual students can develop the dimensions of Academic Literacy in Mathematics (ALM) in classroom discussions. But, there is a need for empirically-validated principles for fostering such discussions. This research used ALM as a framework to create a unit of instruction on linear rates of change for ninth grade mathematics in which multilingual students benefit from discussions. Project-specific design principles are presented along with qualitative analysis of classroom discussions from each phase of the project. The results illustrate how discussions in the redesigned lessons contributed to developing the interrelated dimensions of ALM among multilingual learners. The work concludes with a discussion of how the project-specific design principles can serve as a framework for fostering discussions in other multilingual secondary mathematics learning environments.
\end{abstract}

Keywords Algebra $\cdot$ Rate of change $\cdot$ Design experiment $\cdot$ Multilingual learners $\cdot$ Mathematical discourse

\section{Introduction}

Many emerging multilingual students in US secondary schools have limited opportunities to learn grade-level mathematics. Secondary students classified as English Learners ${ }^{1}$ (ELs) are often "enrolled in low-track curricula with limited exposure to either the content or discourse necessary to enter into higher education" (Callahan, 2005, p. 321), which causes educational inequities for such students (Gándara \& Contreras, 2009). The Academic Literacy in Mathematics (ALM) framework provides a lens for both analyzing language demands of school mathematics and for designing learning environments in which emerging multilingual students can learn grade-level mathematics (Moschkovich, 2015). One way to develop ALM is through fostering classroom mathematical discussions (Moschkovich \& Zahner, 2018). The potential utility of mathematical discussions, and the relative lack of discussions in US secondary mathematics classrooms serving multilingual learners, highlights a need for research on designing mathematics learning

William Zahner

bzahner@sdsu.edu

1 Center for Research in Mathematics and Science Education, San Diego State University, 6475 Alvarado Road Suite 206, San Diego, CA 92120, USA environments where emerging multilingual students can benefit from discussions.

\subsection{Academic literacy in mathematics}

Over the past 20 years, research on language in mathematics has expanded beyond a focus on word problems to include the lexical, syntactic, and discursive aspects of language in school mathematics (Barwell et al., 2017). The ALM framework follows this expansion and includes three interrelated dimensions under the umbrella of academic literacy: (a) developing mathematical proficiencies, (b) engaging in mathematical practices, and (c) participating in mathematical discourse (Moschkovich, 2015). Mathematical proficiencies are forms of expertise, knowledge, and facility for doing mathematics (National Research Council, 2001). In the US context of this research, many emerging multilingual learners experience remedial mathematics classes focused on learning procedures (Kanno \& Kangas, 2014), limiting their opportunities to develop other proficiencies such as adaptive reasoning or conceptual understanding. Mathematical practices are culturally

\footnotetext{
1 We use English Learner (EL) to describe multilingual students who were assigned this classification by the school. However, the term EL is problematic as it focuses on what students lack rather than their resources. We use multilingual students and emerging multilingual students to highlight their assets.
} 
Fig. 1 Illustration of how ALM was used in both development of design principles and analysis of project-developed lessons. Top half done in (Moschkovich, 2015) and (Moschkovich \& Zahner, 2018)

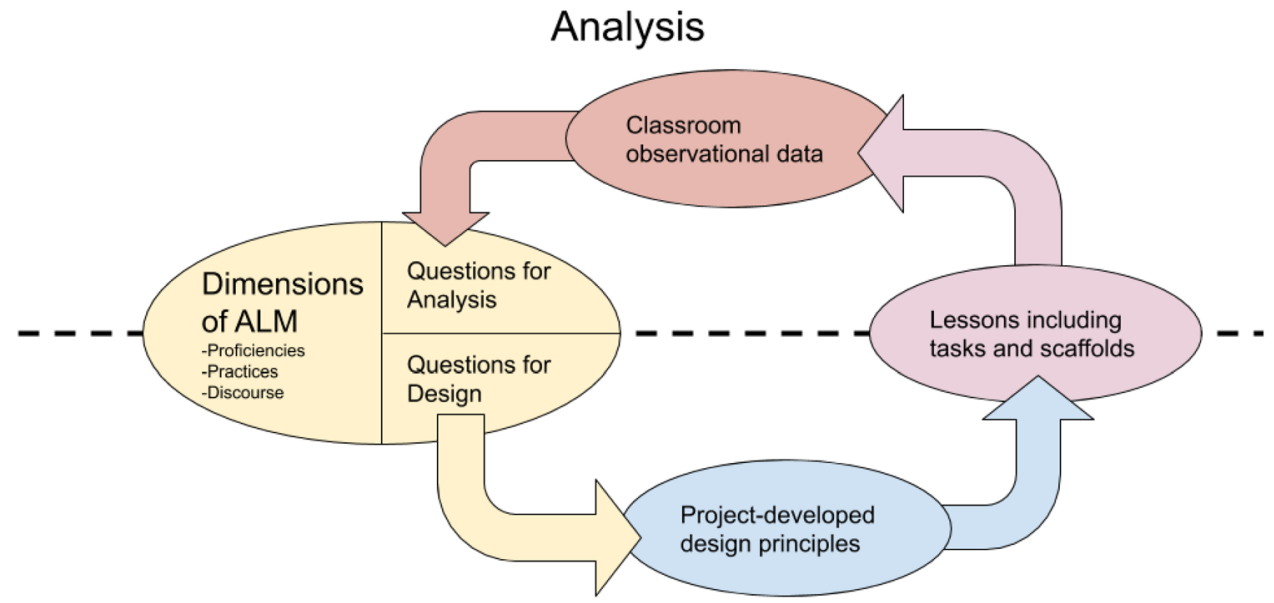

Design organized and socially mediated mathematical activities, such as problem solving, modeling, and proving. Policy documents such as the Common Core State Standards for Mathematics envision students engaging in mathematical practices while learning facts, concepts, and procedures (NGACBP \& CCSSO, 2010). Finally, mathematical discourses are ways of using language and other semiotic tools to signal membership within a broader mathematical community (Moschkovich, 2002). The dimensions of ALM are intertwined in teaching and learning (Moschkovich \& Zahner, 2018).

\subsection{Research aim}

One format for developing the interrelated strands of ALM in multilingual classrooms is mathematical discussions (Moschkovich \& Zahner, 2018). In the following, we present results from a design research effort with the aim of developing ALM in multilingual secondary mathematics classrooms through fostering mathematical discussions. As illustrated in Fig. 1, the dimensions of ALM framed data analysis, the project-specific design principles, and the unit/ lesson designs. While there is a growing body of descriptive research on language in mathematics, this study fills a gap in the field since there is still relatively little design research on fostering mathematical discussions in multilingual classrooms (Erath et al., 2021). The empirical part of this paper will address the following research questions:

RQ1: How was student participation in discussions supported by the lesson design features?

RQ2: How was the development of ALM among multilingual students supported by student participation in discussions?

\section{Literature review}

A substantial body of research investigates the importance of language(s) in mathematics learning (reviewed in, e.g., Barwell et al., 2017; de Araujo et al., 2018). Below we review findings from two subsets of this literature related to ALM: (a) research on discussions in mathematics classrooms, and (b) design research focused on multilingual mathematics classrooms.

\subsection{Discussions in mathematics classrooms}

Students, including emergent multilingual students, can learn mathematics by engaging in classroom discussions (Erath et al., 2018; Gutiérrez, 2002; Moschkovich, 1999; O'Connor, et al., 2015). One beneficial form of discussion occurs when classroom members engage in sustained dialogue about mathematical concepts, meanings, and procedures. For example, O'Connor (2001) analyzed a discussion in which fifth-grade students debated whether "any fraction can be turned into a decimal" (p. 144). Through discussion, students developed mathematical understandings while engaging in collective argumentation, illustrating the interplay of learning mathematical practices and content (Moschkovich, 2015). In contrast with the discussion in O'Connor (2001), most traditional mathematics classroom talk follows an Initiation-ResponseEvaluation (IRE) pattern (Cazden, 2001; Herbel-Eisenmann et al., 2013), which is characterized by the teacher asking known-answer questions, students answering, and the teacher offering evaluations. In an experimental study, O'Connor et al. (2015) compared student learning in a traditional class taught using IRE discourse to student 
learning in a more authentic discussion-based class about the same content. They showed that discussion-based teaching led to improved student learning outcomes as measured by a curriculum-aligned assessment.

Moschkovich (1999) argues that, with appropriate scaffolding, such authentic mathematical discussions can be beneficial for emerging multilingual students. Particularly, discussions provide a venue where emerging multilingual students can develop the dimensions of ALM (Moschkovich $\&$ Zahner, 2018). Since IRE is the default mode of classroom discussion, and most emergent multilingual students experience low-track classes characterized by low-level discussions (Callahan, 2005; Kanno \& Kangas, 2014), efforts to transform patterns of talk in multilingual secondary mathematics classrooms will require intentional designs and appropriate teaching practices. Additional research is needed to create an empirical basis for the use of specific design principles and teaching practices (Erath et al., 2021).

\subsection{Interventions and design research in multilingual settings}

Recent interventionist research focused on language and mathematics highlights that students' mathematical conceptual development is inextricably linked to their development in the use of language(s), semiotic resources, and discourse practices. For example, Chval et al. (2014) collaborated with elementary teachers to unpack the language demands while planning mathematics lessons for multilingual elementary students. They noted that for emergent multilingual students, it was critical that teachers support students to overcome the non-mathematical language demands of problem contexts in order to benefit from conceptually focused mathematics curriculum materials. Prediger and Zindel (2017) delved deeper into the link between mathematics and language and explicated the conceptual facets of understanding functional relationships. They developed a model connecting mathematical conceptual learning processes in the domain of function (unfolding and compacting) to corresponding languagerelated learning processes (decomposing and condensing).

In some prior research on language and mathematics, mathematics development goals and language learning trajectories have been considered separately (Wylie et al., 2018). Yet, due the inextricable link between conceptual and linguistic development, a design heuristic arising from recent interventions is that instructional designers should integrate language development goals and mathematical learning goals (Pöhler \& Prediger, 2015; Prediger \& Zindel, 2017). For example, Pöhler and Prediger's (2015) study of integrated learning trajectories for understanding percentages used such an approach. The connected mathematical and language development goals were supported by macro-scaffolding of language as well as the use of carefully chosen semiotic resources (e.g., percent bar diagrams) to support reasoning. Building upon the research-based call for integrating language and mathematics, we used ALM as a design and analysis framework. ALM is especially apt because it aligns with the situated sociocultural theoretical perspective, described next.

\section{Theoretical background}

The overarching theoretical framework for this work is a situated sociocultural perspective on learning, where learning mathematics includes appropriating problem-solving tools (Wertsch, 1991), developing engagement in practices (Moschkovich, 2007), and participating in disciplinary discourses (Forman, 1996). This theoretical perspective is reflected in our design effort via the ALM framework (Moschkovich, 2015). With its focus on proficiencies, practices, and discourse, ALM integrates aspects of academic literacy that are traditionally viewed from more cognitive perspectives (e.g., proficiencies such as understanding mathematical concepts and procedures) with aspects of literacy that are more sociocultural and discursive (e.g., participation in mathematical practices and discourse). This view of literacy in mathematics shifts from limited views of (academic) language as vocabulary to a sociocultural perspective of academic language where meanings are situated in the practices and discourses of the mathematics classroom (Moschkovich, 2015; Moschkovich \& Zahner, 2018). Importantly, this reconceptualization of language can position the language(s) of multilingual students who do not yet know the mathematical vocabulary in the language of instruction as resources rather than deficits (Moschkovich, 2013).

\section{Methods}

\subsection{Methodological framework: design research}

Design research (DR) is an iterative methodology where researchers purposefully design a learning environment, explore phenomena that emerge as a result of the design, and refine the design for future iterations while at the same time developing local theories (Cobb et al., 2003; Prediger et al., 2015). This interventionist approach was necessary for this investigation because mathematical discussions are relatively rare in US classrooms serving English learners (Callahan, 2005) and thus unlikely to arise spontaneously. In this project, each design cycle included: (a) collecting data during observations of a unit of instruction (a sequence of topically-related lessons), (b) analyzing the observation data, (c) redesigning the unit, and (d) observing teaching and learning interactions in the redesigned unit. Research 
Fig. 2 Phases of the design experiment

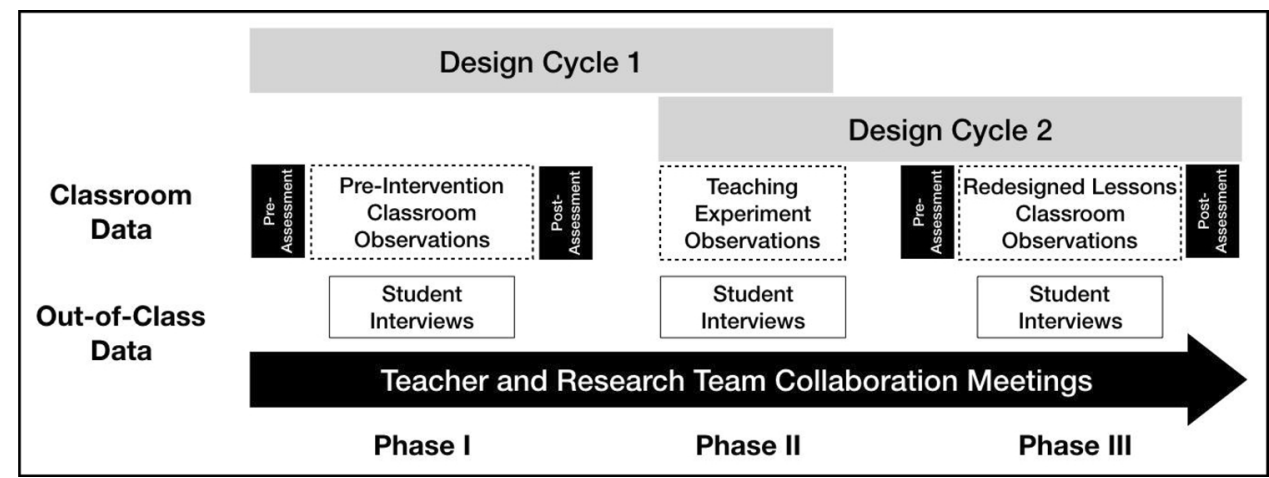

occurred in two cycles (Fig. 2), and the design team included university-based researchers as well as teachers from the research site.

We report on the redesign of a curriculum unit introducing the slope of linear functions. At the school research site, the topic of slope was introduced once per academic year in ninth grade. Thus, the design cycles spanned multiple academic years to fit the school's yearly curriculum sequence. In the first design cycle, the researchers observed the teachers as they taught the unit introducing slope without intervention (Phase I in Fig. 2). For the purpose of triangulating data from classroom observations (Miles et al., 2014), the researchers conducted task-based interviews with students and collected pre-unit and post-unit written assessments (which are analyzed elsewhere). At the end of Phase I, the researchers and teachers met to reflect on the data and redevelop the unit with the goal of developing the dimensions of ALM. Through this reflection process, the project design principles (Sect. 5) were first developed. The new unit was pilot tested in an after-school teaching experiment (Phase II in Fig. 2). Most of the teaching experiment lessons were taught by a researcher, but the seventh lesson of Phase II was taught by a collaborating teacher. We engaged in another cycle of reflection and redesign between Phases II and III as the unit was prepared for use during the regular school day.

\subsection{Setting and data sources}

This paper analyzes class discussions from three lessons recorded in ninth grade integrated mathematics classes at City High, ${ }^{2}$ a linguistically diverse, urban high school located near the US-Mexico border. City High was chosen to situate this research in an environment reflective of the inequitable educational experiences of students from racial, ethnic, and linguistic minorities in the US (Gándara \& Contreras, 2009). At City High, 77\% of students were identified as Latinx, 12\% Asian, 7\% African American, and 4\% other.

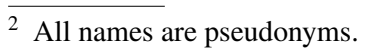

About $89 \%$ of students were from low-income families. Thirty percent of all students at City High were classified as ELs.

This analysis focuses on classroom observation data, which included field notes, video recordings, transcripts of verbal interactions, and images of student work. In other papers, we present analyses of results from the written assessments (Zahner et al., 2020). In the present analysis, we focus on three classes taught by Mr. S, a teacher at City High. Multiple teachers joined the project across all three phases, but Mr. S was the only teacher who participated across all phases of the project ("teacher turnover" is a common problem in US schools). Mr. S was certified to teach secondary mathematics and had six years of experience at the start of the study. He spoke Spanish and English and identified as Latinx. He mostly used English in class, but he used Spanish when interacting with students individually or in small groups.

\subsection{Focal lessons: selection and summary}

In Sect. 6, we compare excerpts selected from one lesson from each phase. The Phases I and III focal lessons were chosen because they addressed the same content and were taught later in the unit. Although the topic was different, the Phase II focal lesson was chosen because it was also taught by Mr. S, keeping the teacher consistent across phases. Each observation was summarized in a structured form describing the lesson content, sequence of activities, and transitions, along with ethnographic fieldnotes and researcher reflections (Miles et al., 2014). These structured summaries were used when selecting lessons and excerpts for deeper qualitative analysis. Table 1 provides an overall summary of data for each phase, as well as details about the focal lessons.

\subsection{Ethnographic discourse analysis}

The analysis of classroom interactions in this study is rooted in ethnographic discourse analysis (Gee \& Green, 1998). Ethnographic discourse analysis seeks to uncover how social 
Table 1 Descriptive information of the three sets of classroom observations and focal lessons

\begin{tabular}{|c|c|c|c|}
\hline & Phase I & Phase II & Phase III \\
\hline \multicolumn{4}{|l|}{ Overall unit } \\
\hline Term & Fall 2017 & Fall 2018 & Fall 2019 \\
\hline Duration & $\begin{array}{l}8 \text { lessons, } \\
90 \text { min each }\end{array}$ & $\begin{array}{l}10 \text { lessons, } \\
60 \text { min each }\end{array}$ & $\begin{array}{l}10 \text { lessons, } \\
90 \text { min each }\end{array}$ \\
\hline Setting & Regular school day & $\begin{array}{l}\text { After school teaching experi- } \\
\text { ment }\end{array}$ & Regular school day \\
\hline \multicolumn{4}{|l|}{ Focal lesson } \\
\hline Topic & Focal lesson & $\begin{array}{l}\text { Generalizing same speed rela- } \\
\text { tionships }\end{array}$ & $\begin{array}{l}\text { Generalizing same } \\
\text { speed relationships }\end{array}$ \\
\hline Number of students & 28 & 18 & 33 \\
\hline$\%$ Classified $\mathrm{ELs}^{\mathrm{a}}$ & $18 \%^{\mathrm{b}}$ & $39 \%$ & $38 \%$ \\
\hline$\%$ Ever ELs $^{\mathrm{a}}$ & $50 \%$ b & $100 \%$ & $90 \%$ \\
\hline Time teaching new material & $48 \mathrm{~min}$ & $63 \min$ & $77 \mathrm{~min}$ \\
\hline Whole-class discussion (\%) & $41 \min (85 \%)$ & $29 \min (46 \%)$ & $46 \min (60 \%)$ \\
\hline Group discussion or individual (\%) & $7 \min (15 \%)$ & $34 \min (54 \%)$ & $29 \min (40 \%)$ \\
\hline
\end{tabular}

${ }^{a}$ ELs are students in each class who were classified as English learners at the time of the study. "Ever ELs" includes ELs and students who were classified as ELs in earlier grades

${ }^{\mathrm{b}} \mathrm{Phase}$ I data are underestimates due to not all students consenting to the study

and cultural processes are created through discourse, and, in turn, how discourse reflexively shapes social and cultural processes (Schiffrin, 1994). Gee and Green (1998) propose both an analytical framework and guiding questions for such discourse analysis. Specifically, they suggest examining the material, activity, semiotic, and sociocultural dimensions interactions. Moschkovich and Zahner (2018) adapted these foci in articulating a set of analytical questions focused on the dimensions of ALM (see Table 2).

In Sect. 6, we present qualitative analyses of excerpts of classroom interactions from each phase of the design research. Within each selected focal lesson, we used the field notes and structured summaries together with the analysis questions in Table 2 to identify moments where the talk and interactions reflexively related to the dimensions of ALM. Specifically, we identified moments in which the central mathematical focus of each lesson (proficiencies) was highlighted during the whole-class discussion. Next, we annotated the excerpts and added comments to unpack how the dimensions of ALM were relevant to the excerpt. In relation to proficiencies, we asked, what evidence is there that the interaction focuses on applying a known procedure versus developing a conceptual understanding of the topic? In terms of mathematical practices, we asked, what evidence do we see of students using disciplinary practices (e.g., explaining, justifying, modeling) or practices associated with school mathematics (e.g., producing answers)? Finally, we focused on disciplinary discourse (e.g., looking for evidence of dialogue, authentic questions, and use of disciplinary terminology) or school discourse practices (e.g., IRE sequences, and the use of school mathematics terms like "rise over run"). For example, in Excerpt 1, we noted the teacher and students used IRE patterns of discourse and focused on applying a formula. This is contrasted with the dialogue in Excerpt 2 where the teacher and students asked more authentic questions of each other and generalized a process.

\section{Design principles and overview of redesigned unit}

\subsection{Design principles}

We developed three design principles (DPs) across the phases of this work:

DP1: Use a primary conceptual focus across the unit and carefully choose problem contexts that support the conceptual focus,

DP2: Integrate language goals linked to mathematical content goals,

DP3: Incorporate discourse supports.

While other works have developed additional design principles (Erath et al., 2021), these three principles were most relevant to our goals of promoting discussions in multilingual classrooms and developing the dimensions of ALM. In Table 2, we show how the design principles related to the dimensions of the ALM framework, the corresponding analytical question(s), and our rationale for the principle. Note that the dimensions of ALM are interdependent, thus Table 2 


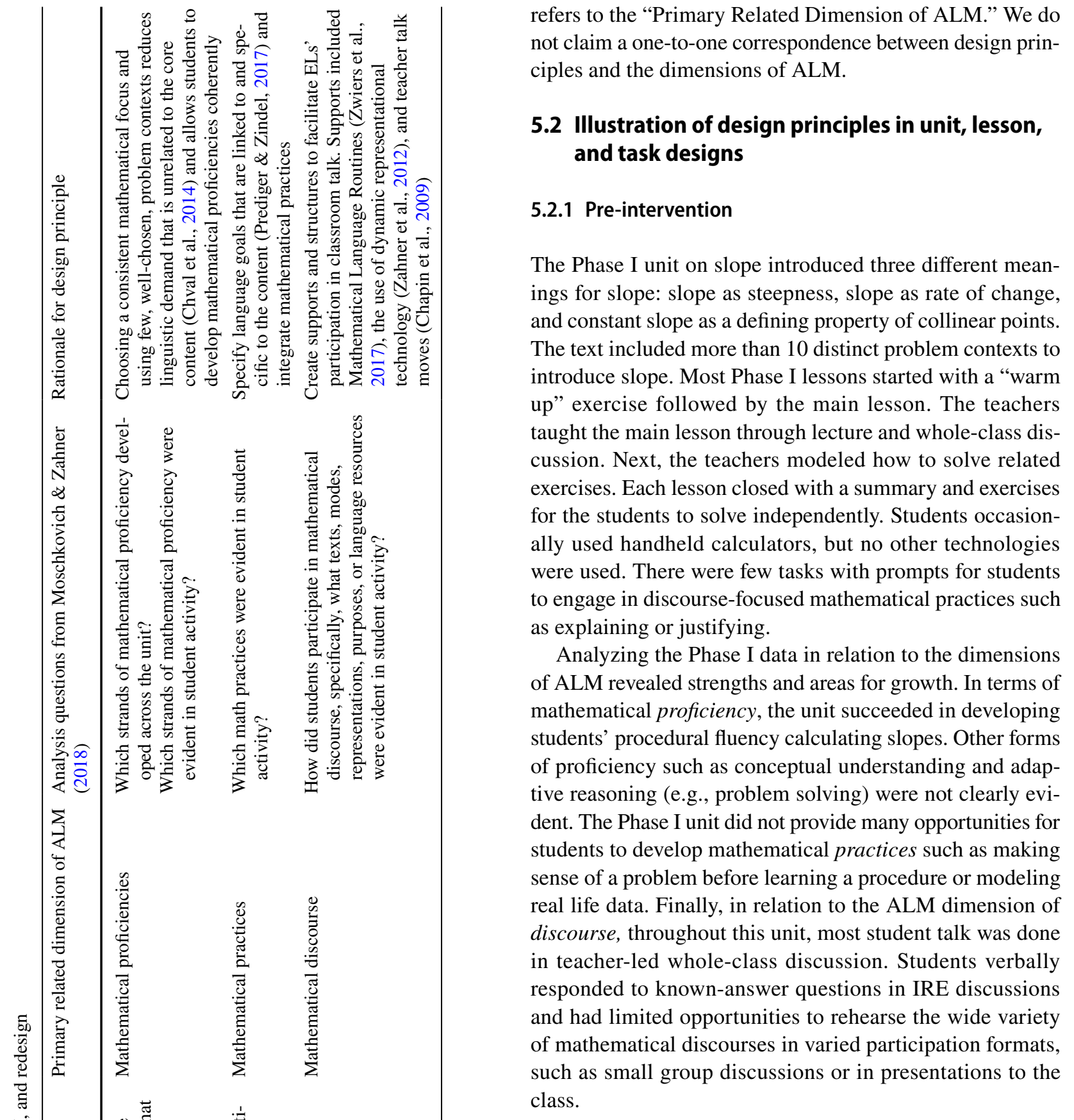

\subsubsection{Unit redesign}

After Phase I, a redesigned unit was created to improve opportunities for students to develop the dimensions of ALM. In terms of proficiencies, a critical focus in designing lessons for ELs is developing conceptual understanding alongside procedural fluency (Moschkovich, 2013; Moschkovich \& Zahner, 2018). Thus, as noted in DP1, the redesigned unit had one primary conceptual focus: understanding slope as a rate of change (Lobato et al., 2010; Thompson, 1994). Relatedly, few problem contexts were used to decrease concept-irrelevant linguistic demand and 


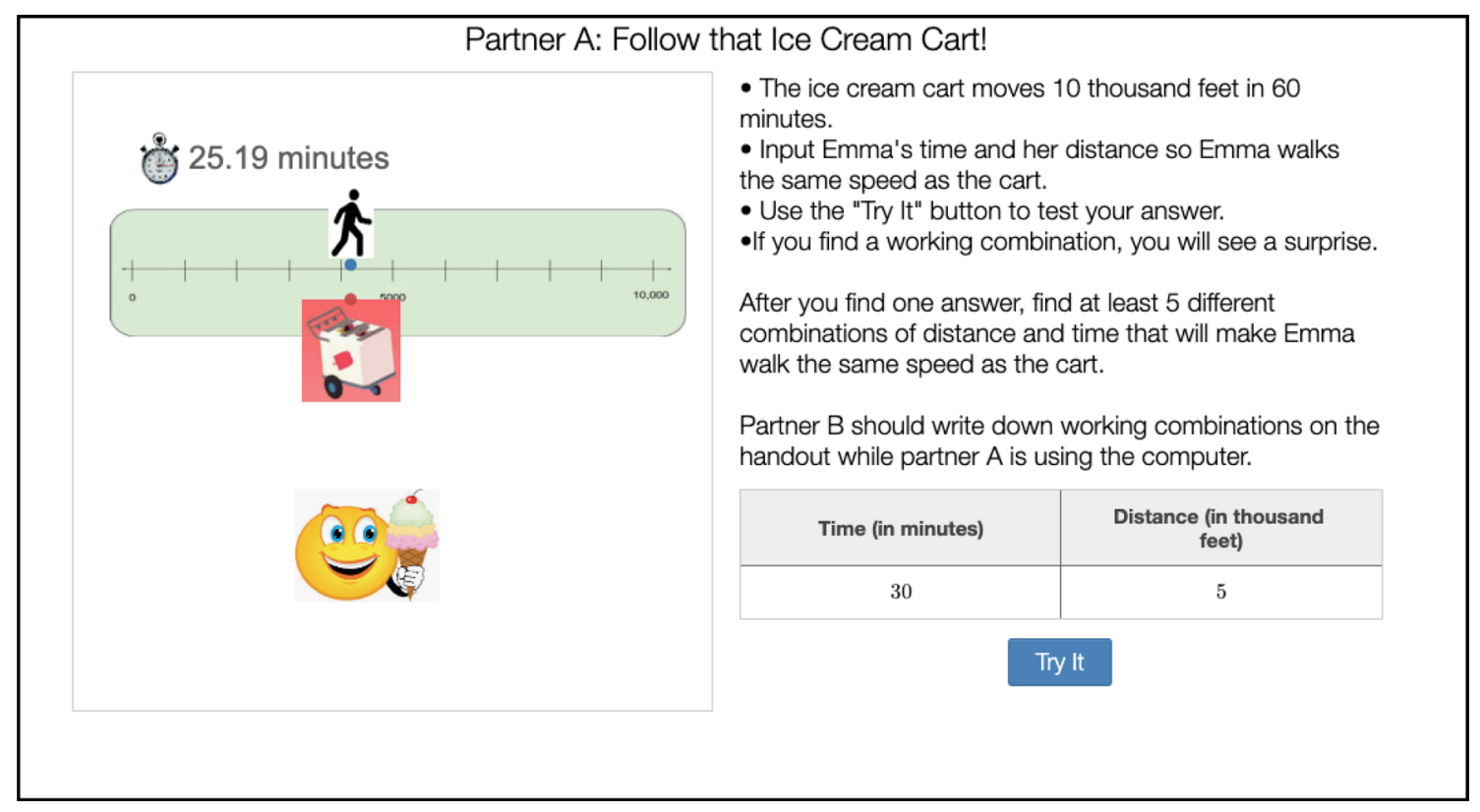

Fig. 3 A screen image of the simulation used in Generalizing Same Speed Walks

support the conceptual focus (Chval et al., 2014). The redesigned unit was built around stories of distance-time-speed relationships, and used dynamic representational technology (Zahner et al., 2012) to support student engagement with problem contexts.

For example, one lesson, Generalizing Same Speed Waks, focused on a character, Emma, chasing an ice cream cart moving at a rate of 10 thousand feet every $6 \mathrm{~min}$ (ice cream vendors are a common sight near City High). To get ice cream Emma needed to move at the same speed as the cart. Students used a digital simulation (Fig. 3) to input and test combinations of time and distance that would make Emma move at the same speed as the ice cream cart. Then, the teacher facilitated a discussion synthesizing methods students used to solve the problem (see Table 4 below).

All of the redesigned lessons included mathematical language goals ${ }^{3}$ that focused on engaging students in mathematical practices such as generalizing, describing procedures, and justifying claims. Consistent with DP2, the language goals focused on specific mathematical practices that supported each lesson's mathematical goals. Many mathematical practices are not exclusively realized in verbal language. However, given this project's focus on promoting ALM through engaging students in discussions, we highlighted language-intensive practices in these goals. Figure 4 shows the goals for the Generalizing Same Speed Walks

\footnotetext{
3 The school lesson planning guidelines required each lesson include language goals. Prior to this project, those goals, if stated at all, were usually a list of vocabulary words in the lesson.
}

lesson which targeted the practices of quantitative reasoning and generalizing. Importantly, students were not given formulas to apply. Instead, students were expected to explore a model, attend to the relationships among distance time and speed embedded in the given mathematical problem, conceptualize that relationship, and subsequently generalize and describe a process for calculating same speed walks.

Finally, to promote broad student engagement in mathematical discourse, the redesigned lessons incorporated discourse supports (DP3), such as (a) alternating whole-class and small-group discussions, (b) integrating mathematical language routines (MLRs; Zwiers et al., 2017), and (c) using technology and dynamically linked representations (Zahner et al., 2012). The MLRs are a tool set of adaptable structures, distilled from prior research, designed to amplify, assess, and develop students' language. For example, in a Collect and Display MLR (briefly defined in Fig. 4), a teacher asks open-ended questions in order to solicit and publicly display student-generated language. This public display then becomes a shared support for student-generated talk. Connecting to the recommendations in Moschkovich $\&$ Zahner (2018), the discourse supports were intentionally chosen to vary the texts, modes, and interaction formats used by the students.

\section{Qualitative analysis and results}

A primary goal of this work was to develop ALM through classroom discussions. Here we illustrate how discussions supported the development of ALM across each project 
Fig. 4 Page from teacher guide showing mathematical content goals, mathematical language goals, and mathematical discourse supports in the Emma's Average Rate lesson from Phase III

\section{Generalizing Same Speed Walks}

\begin{tabular}{|c|c|}
\hline $\begin{array}{l}\text { Mathematical Goals } \\
\text { - Create multiple distance time pairs for } \\
\text { same speed challenges. } \\
\text { - Reason quantitatively about the invariant } \\
\text { multiplicative relationships for } \\
\text { distance-time-speed. } \\
\text { - Generalize distance-time-speed } \\
\text { relationship for different combinations of } \\
\text { distance-time-speed. } \\
\text { - Generalize to a variable. }\end{array}$ & 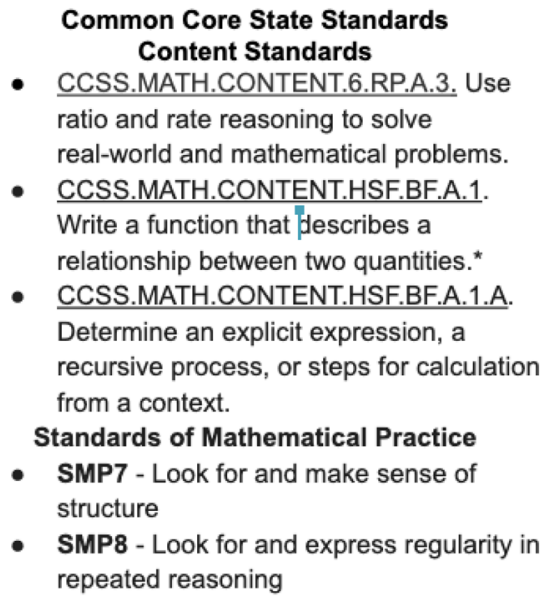 \\
\hline $\begin{array}{l}\text { Mathematical Language Goals } \\
\text { - Attend to quantities in } \\
\text { distance-time-speed relationships, using } \\
\text { multiplicative language to relate distance, } \\
\text { time and speed. } \\
\text { - Make generalizations about multiplicative } \\
\text { distance-time-speed relationships. "To find } \\
\text { the speed I divide the distance by time." } \\
\text { "The time is always six times the } \\
\text { distance." }\end{array}$ & $\begin{array}{l}\text { LRs to support Language Goals } \\
\text { MLR2: Collect and Display } \\
\text { Capture students' oral words and } \\
\text { phrases into a stable, collective } \\
\text { reference. } \\
\text { MLR7: Compare and Connect } \\
\text { Compare and contrast different } \\
\text { mathematical approaches, } \\
\text { representations, examples, } \\
\text { concepts, and language. }\end{array}$ \\
\hline \multicolumn{2}{|c|}{$\begin{array}{l}\text { Student Facing Goals } \\
\text { - I can create multiple distance-time pairs for a given speed. } \\
\text { - I can create an equation that represents a given-time relationship. } \\
\text { - I can find the time given a distance and speed (or vice versa). }\end{array}$} \\
\hline $\begin{array}{c}\text { Lesson Gloss } \\
\text { - Ratio } \\
\text { - Distanc } \\
\text { - Time }\end{array}$ & $\begin{array}{l}\text { - Equivalent } \\
\text { - Speed } \\
\text { - Rate }\end{array}$ \\
\hline
\end{tabular}

Phase. The topic of the Phases I and III focal lessons was average rates of change. The Phase II lesson (which was chosen because Mr. S taught it) was about generalizing same speed walks.

\subsection{Average rate of change in Phase I}

The Phase I class on average rates of change occurred after lessons on calculating the slope of lines using "rise over run." As usual, the class started with a review of procedural problems. Then, Mr. S posted two goals: (a) "students will review or learn the property of speed and slope as a rate of change" and (b) "students will calculate the average speed between two points on a distance-time graph." The lesson then followed the traditional sequence of teacher presentation, whole-class practice, and individual practice (Lampert, 1990). In Table 3, we illustrate a brief moment of interaction that was typical of the Phase I lessons. In this excerpt, Mr. S led the class through a series of questions to find the speed during the first segment of the graph in Fig. 5. Underlined words and comments in each transcript are used to highlight mathematical proficiencies, practices, and discourse, aligning with the dimensions of ALM.

This lesson had strengths insofar as Mr. S had a clear goal linked to grade-level curricular expectations. He also made efforts to solicit participation from multiple students. Yet, through the lens of the dimensions of ALM, this interaction presented limited opportunities for Mr. S's linguistically 
Table 3 Excerpt from Phase I average rates lesson

\begin{tabular}{lll}
\hline Turn & Utterance & Comment \\
\hline 1 & $\begin{array}{c}\text { T: The speed from point A, now according to the definitions that you guys wrote down, } \\
\text { that you should have in your notes, how do you find the speed? Distance div- look I } \\
\text { have it written here. Distance divided by time. Okay, so from point A, or from point O } \\
\text { to point A, what's the distance that we traveled here? }\end{array}$ & $\begin{array}{c}\text { T references the formula that was given at the } \\
\text { start of class } \\
\text { Initiation }\end{array}$ \\
& $\begin{array}{l}\text { Multiple Students: Seventy-five } \\
\text { T: } \text { Seventy five. So the distance is seventy five. How long did it take Tia to ride her motor- } \\
\text { cycle seventy five miles? }\end{array}$ & $\begin{array}{l}\text { Response } \\
\text { Implicit Evaluation followed by next initiation }\end{array}$ \\
& Multiple Students: An hour &
\end{tabular}

$(())$ are comments, (.) is short pause, [ indicates overlapping talk, \{\} are translations, $x x x$ indicate inaudible talk, and () indicate uncertain transcriptions. Underlining highlights parts of the transcript for comment

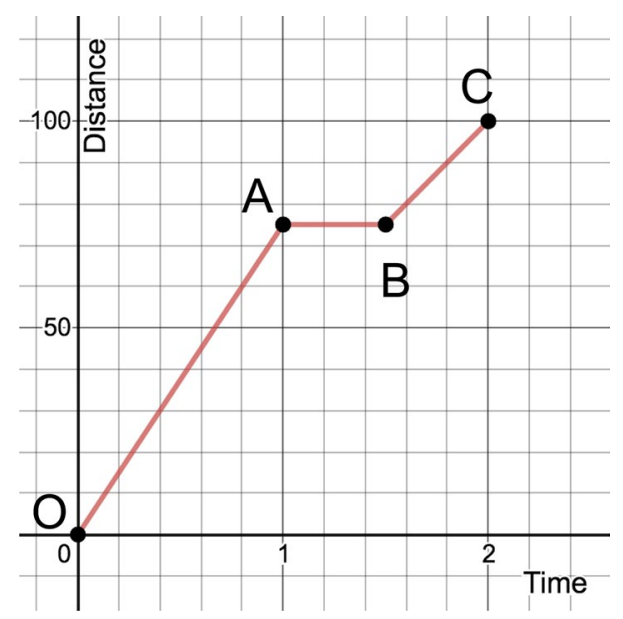

Fig. 5 The graph discussed in Table 3

diverse students to develop multiple forms of mathematical proficiency, engage in mathematical practices, or to use mathematical discourse. The primary form of mathematical proficiency developed in this lesson was procedural, specifically using the average rate formula (line 1). There was limited evidence of students engaging in disciplinary mathematical practices such as explanation or justification. Instead, most student turns were short answers to known answer questions. Finally, and related to the practices, the student engagement in mathematical discourse was also minimal. In place of disciplinary discourse, the interaction in Table 3 reflects a traditional classroom discussion with multiple IRE sequences (Cazden, 2001). These discourse patterns were fairly consistent in most Phase I lessons.

\subsection{Same speed combinations in Phase II}

Mr. S taught one lesson during the Phase II teaching experiment. The lesson goals are in Fig. 4. Prior to the excerpt in Table 4, students worked in groups to find five distancetime combinations that made Emma move at the same speed as the ice cream cart (Fig. 3). In Table 4, Damariz, a former EL, shared a method to find combinations to make Emma walk the same speed as the cart. During this interaction, there were contributions from former ELs (Hala, Ana, and Javier), as well as students classified as ELs (Teo and Cristobal).

Turning to the dimensions of ALM, the primary proficiencies developed in this lesson were developing conceptual understanding and engaging in open-ended problem solving. Specifically, students were developing a conceptual understanding of speed through investigating and explaining a pattern using multiple representations. The primary mathematical practices were explaining a process and developing an algorithm (of sorts). Damariz was pressed to justify her method in questions from other students (lines 25 and 27). Finally, the students were engaging in discourses aligned with the discipline of mathematics. Damariz's activity of standing at the board and explaining her procedure echoes the traditional school math lesson. However, Damariz constructs new identities for herself and her peers through her discourse (e.g., taking the pen and writing on the board, and the shift in her use of "we"). While the first "we" in line 20 appeared to refer to her group, the second "we" appeared to signal Damariz's affiliation with a broader mathematical community. Additional moves highlighted this interaction was not a traditional school math discussion. For example, the students pressed Damariz for clarification (lines 25 and 27), and contributed additional ways to explain or describe Damariz's method (line 29). Finally, note in this illustration how the dimensions of ALM are intertwined and interdependent. That is, the mathematical practices and discourse that are evident in Table 4 were facilitated by discussing tasks intentionally designed to develop broader forms of proficiency.

\subsection{Average rate of change lesson in Phase III}

The lesson analyzed here was the replacement of the Phase I lesson described in Sect. 6.1. The Phase III lesson on 
Table 4 Damariz shares her method to find distance time combinations

\begin{tabular}{ll}
\hline Turn & Utterance \\
\hline 1 & T: The question that I want you to answer says "Explain why do
\end{tabular}
all the same speed walks follow this pattern?" Why were all the graphs the same?

2 Ana: Because it's all, they're all equivalent to each other. All the (.) like, the time and the distance, they're all equivalent

3 T: The time and the distance... Well they weren't all equal because we got...

4 Ana: But, they have, like, how do I say

5 Hala: Has a similar pattern

6 T: Sixty and ten. Yeah, that's kind of what we want to explain. We got six and one. What was another one that we got? ((4 s pause)) What were some of your answers?

7 Damariz: Wouldn't it be because they [they have the same equa$\underline{\text { tion? }}$

Comment

Initial prompt is to explain

"Equivalent" is an accurate description

T does not affirm Ana's response

Ana struggles to find alternative phrasing

Builds on Ana's turn

Affirms Hala. Prompts students to list combinations

Not clear if this turn was heard by $\mathrm{T}$

Ana: [fifteen

9 T: fifteen and...?

10 Ana: two point five

11 T: Two point five. They all have the similar ( $4 \mathrm{~s}$ pause $))$. This is the question I want the answer to. How come they ((points to numbers)) all work? What do they have that's the same?

12 Ana: They're, they're all like. They can ((falling voice))

13 T: Hmm. What else did we get? We got, like twelve and two. We got thirty-six and six. ((writes numbers)) What do you think?

14 Damariz: You can get all these answers (.) With the (.) You see. You see the six and the one? You can get all those answers from that single, like, equation can I say? If you multiply two point five by one you get two point five and if you multiply two point five by six you get fifteen. And if you multiply ten by [one then

15 T: [Hold on. two point five times one and fifteen times... ((teacher writes " $2.5 \times 1$ " and " $15 \mathrm{x}$ " in the blank space on the board))

16 Damariz: No no. Two point five times six

17 T: Two point five times six. ((erases calculations))

18 Damariz: If you mu-, If you multiply the first number that's on like, this side ((Pointing)) by the whole thing. It (.) it's kind of hard to explain but let me show you. ((Stands up, approaches display))

19 T: I would love for you to show me. Teo, can you put that away for a sec? Can you guys give her her your attention please?

20 Damariz: ((Draws a box around the row "6 1" on the board)) So, so right here? This is the overall equation that we used for everything else. So if we list every number that we have here ((indicating the numbers in the distance column)) we multiply this number ((pointing to the 1 in the 6-1 row)) by these both numbers to get both numbers like that

21 T: Ok, so like to get this one ((points at the row with "15 2.5")), what did you multiply by?

22 Damariz: To get this one ((2.5 in distance column) ) you had to multiply two point five and to get to fifteen you have to multiply six times two point five

23 T: So you're saying if you multiply six times the same two point five, you get fifteen

24 Damariz: Yeah. And if you [multiply

25 Teo: [I'm confused

26 Hala: Multiply them

27 Cristobal: Can you please show us?

T directs students' attention to Damariz

Damariz uses idea of equation

Situated meaning of "we" shifts

T changes the written prompt to explain to "how come they all work"

Open ended question

Damariz changes focus to explaining a process to generate equivalent combinations

$\mathrm{T}$ revoices student

Student requests clarification from other student

Clarification request 
Table 4 (continued)

\begin{tabular}{lll}
\hline Turn & Utterance & Comment \\
\hline $28 \quad$ & $\begin{array}{l}\text { Damariz: Ok, so let's say. Let's use four right now. Six and one. } \\
\text { ((Writes "6" and "1" on the white space on the board.)) In order, } \\
\text { so in order to make them equal, you multiply, oh sorry, you multi- } \\
\text { ply this number by four and this number by four. ((Writes smaller } \\
\text { " } \times 4 \text { " by } 6 \text { and by the } 1) \text { ) So you can get like an equal equation. } \\
\text { So it would be four (.) twenty four }\end{array}$ & $\begin{array}{l}\text { Damariz uses non-decimal example to explain to Teo and Cristobal } \\
\text { concept of equivalent }\end{array}$ \\
& $\begin{array}{l}\text { Javier: So, what you're saying is what you do to one side, [you do it } \\
\text { to the other side }\end{array}$ & Javier revoices and names this procedure \\
$30 \quad$ Damariz: [Yeah, what you do to one side you do to the other side & Uptake of Javier's naming \\
\hline
\end{tabular}

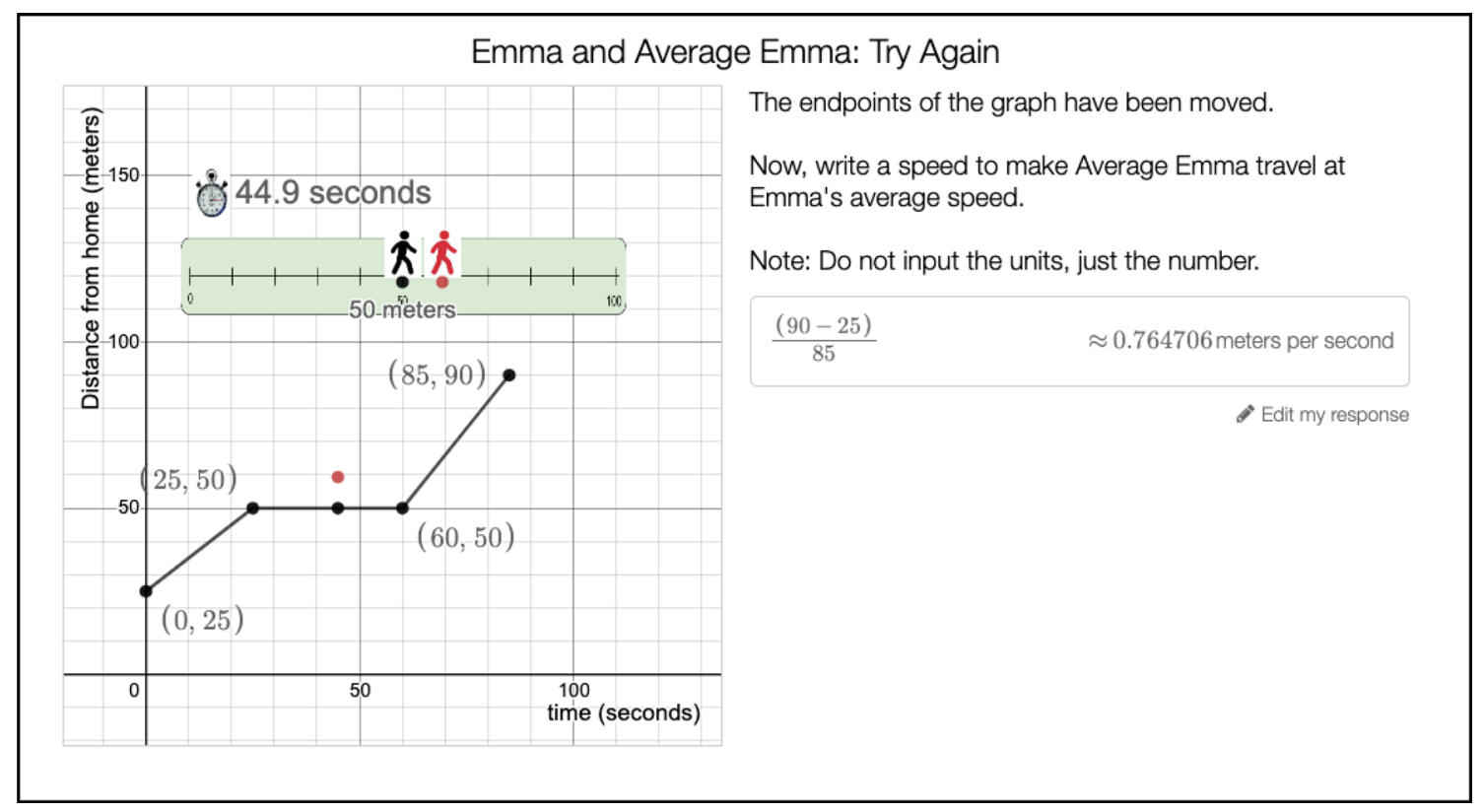

Fig. 6 The prompt discussed in Table 5

average rate of change started with students working in pairs, making sense of and exploring a dynamic model. In the model, Emma walks at rates determined by a piecewise linear graph while another character, Average Emma, walks at a steady pace, starting and stopping at the same location and time as Emma. Mr. S allowed the students to explore the model. Then, he used a Collect and Display MLR (Zwiers et al., 2017) to record what students noticed about the model. During this routine a student used the word constant and Mr. S emphasized that Average Emma traveled at a constant rate while Emma moved at a nonconstant rate. Next, the students were presented with two challenges: (a) finding the speed of Average Emma to make her start and finish at the same time and place as Emma, and (b) finding the speed for Average Emma if the initial position of Emma was 25 rather than zero (Fig. 6). Students worked on the challenge independently. Then, in
Table 5, Mr. S asked Simón to share his method for finding the rate of Average Emma.

Turning to the proficiency dimension of ALM, in this excerpt Mr. S highlighted a conceptual focus by repeatedly pressing Simón to name the quantities he was using (lines 5, 7, 9) and connecting the quantities to the graph and context. Also, in line 23, Mr. S deemphasized calculations and highlighted the meaning of the numbers in the calculations in relation to the problem context. This lesson focused on mathematical practices through incorporating problem solving, explaining procedures, and justifying answers in terms of quantities. $\mathrm{Mr}$. S's initial focus on understanding Simón's incorrect answer also modeled that a wrong answer can prompt further investigation. Finally, in terms of discourse, Simón participated in the classroom discourse occupying a space half-way between the teacher and students. Mr. S invited Simón to "help us" at the start of the interaction. That is, Simón was discursively positioned as a helper or teacher of the class (the "us" in "help us"). 
Table 5 Simón explains his method

\begin{tabular}{|c|c|c|}
\hline Turn & Utterance & Comment \\
\hline 1 & $\begin{array}{l}\text { T: Simón, can you stop for a second and help us up here? ((Simón } \\
\text { moves toward the board)) Hmm, what did you try first? First of } \\
\text { all, when you did it wrong, what did you try first? }\end{array}$ & T starts by asking Simón to share an incorrect, but common answer \\
\hline 2 & Simón: Ninety divided by eighty five & \\
\hline 3 & $\begin{array}{l}\text { T: Ninety divided by eighty five. Now tell me where you got that } \\
\text { ninety five? }\end{array}$ & $\begin{array}{l}\text { T asks Simón to explain the meaning of the numbers. We interpret } \\
\text { "ninety five" as misspoken }\end{array}$ \\
\hline 4 & ((Simón points at the right endpoint of graph on the board)) & Nonverbal communication using multiple semiotic resources \\
\hline 5 & T: Yeah. But, what was it? & Focus on quantities \\
\hline 6 & $\begin{array}{l}\text { Simón: Emma was } \mathrm{xxx} \text { and then she stopped at ninety ((points at } \\
\text { the endpoint on the graph while talking) }\end{array}$ & \\
\hline 7 & T: She stopped at ninety. So, that was the distance & Repeats and then adds quantitative information \\
\hline 8 & Simón: Ammhmm ((Agreement)) & \\
\hline 9 & $\begin{array}{l}\text { T: So, this was the distance. And, then what's the eighty five? } \\
\text { ((writes on the board while talking)) }\end{array}$ & Repeating focus on meaning of numbers \\
\hline 10 & Simón: The time & Takes up T's focus on quantities \\
\hline 11 & $\begin{array}{l}\text { T: This was meters and this was seconds. This is the time. } \mathrm{Ok} \text {, but it } \\
\text { didn't work. What happened when you tried it like this? }\end{array}$ & $\mathrm{T}$ shifts to discussing correctness \\
\hline 12 & Simón: Umm It didn’t give me the $\mathrm{xxx}$ & \\
\hline 13 & T: Did you guys...can you guys hear what he is saying? & T asks students to focus on Simón \\
\hline 14 & Multiple Students: ((overlapping)) Yeah... No... Oh, I get it & \\
\hline 15 & T: What was wrong with this one? & \\
\hline 16 & Male Student: The head start & \\
\hline 17 & T: Did Emma travel ninety meters? & $\mathrm{T}$ shifts to IRE format \\
\hline 18 & Multiple Students: No & \\
\hline 19 & $\mathrm{~T}: \underline{\text { How far did she go? }}$ & Initiation \\
\hline 20 & Male Student: Seventy five ... Sixty five & Response \\
\hline 21 & T: Seventy five? Sixty five? How do you know? & Pressing for justification \\
\hline 22 & Student: Because minus twenty five & Response \\
\hline 23 & $\begin{array}{l}\text { T: Minus twenty five. You can actually literally put that into the } \\
\text { calculator ((referring to the entry line on the simulation)). What } \\
\text { does this twenty five represent again? ((T writes on the board } \\
\text { while talking)) }\end{array}$ & $\begin{array}{l}\text { Evaluation } \\
\text { Note T minimizes importance of calculation, and then coordinating } \\
\text { the numbers in the calculation with meanings }\end{array}$ \\
\hline 24 & Student: The twenty five meters head start that she's getting & \\
\hline
\end{tabular}

Table 6 Material, activity, semiotic, and sociocultural dimensions across phases

\begin{tabular}{|c|c|c|c|}
\hline & Phase I & Phase II & Phase III \\
\hline Material & $\begin{array}{l}\text { Classroom tables, projector screen, } \\
\text { notebooks }\end{array}$ & $\begin{array}{l}\text { Classroom tables, projector screen, note- } \\
\text { books, laptops, dynamic technology }\end{array}$ & Same as Phase II \\
\hline Activity & Learn and apply formula, take notes & $\begin{array}{l}\text { Solve non-routine problem in groups, } \\
\text { explain procedures and generalize }\end{array}$ & Same as Phase II \\
\hline Semiotic & Graph and formula & $\begin{array}{l}\text { Graph, formula, table, dynamic technol- } \\
\text { ogy }\end{array}$ & Graph, formula, and dynamic technology \\
\hline Sociocultural & $\begin{array}{l}\text { Traditional IRE format teacher-led } \\
\text { discussion ( } 85 \% \text { whole class discussion, } \\
\text { 15\% group or individual format) }\end{array}$ & $\begin{array}{l}\text { Student initiated a discussion with } \\
\text { authentic questions and student-student } \\
\text { interaction ( } 46 \% \text { whole class discussion, } \\
54 \% \text { group or individual format) }\end{array}$ & $\begin{array}{l}\text { Student invited to lead discussion, Tra- } \\
\text { ditional IRE format teacher-led discus- } \\
\text { sion ( } 60 \% \text { whole class discussion, } 40 \% \\
\text { group or individual format) }\end{array}$ \\
\hline
\end{tabular}

Underlined text indicates changes from Phase I 
Yet, for most of Table 4, Simón responded to the teacher's known-answer questions, a form of talk that parallels the IRE discourse of Table 3. It is possible to imagine several reasons why Simón was not comfortable with this positioning, not least of which was embarrassment at discussing a mistake.

\subsection{Synthesis using ethnographic discourse analysis}

In Table 6, we summarize our analysis of the material, activity, semiotic, and sociocultural dimensions of the interactions in Transcripts 1-3 (Gee \& Green, 1998). The Phase I lesson is recognizable as a traditional US mathematics lesson (Lampert, 1990). Using the Phase I lesson as the baseline, it is notable that the redesigned lessons in Phases II and III transformed aspects of the lesson, particularly,

(a) a shift in material resources with the introduction of computers with dynamic representational technology.

(b) a shift in the activity structure from the teacher presenting a formula and students practicing it to students solving non-routine problems prior to learning a formula,

(c) the introduction of more semiotic resources for reasoning including equations, graphs, tables, and dynamic representations,

(d) a transformation of the sociocultural dimension of classroom interactions from a traditional teacher-led lesson in Phase I to a student driven discussion during Phase II.

The transformation in the sociocultural dimension observed in Phase II is reflected in the percentage of class time that was dedicated to whole-class versus small group or individual format (85\% whole-class in Phase I and $46 \%$ whole-class in Phase II). This transformation did not persist in Phase III (60\% whole-class) and Mr. S reverted back to IRE focused discourse by the end of Table 5. One possible explanation for this shift back to IRE focused discourse is that the time-related pressures of teaching these lessons in the typical school day led to a shift back to the "default" mode of discussion dominated by IRE interactions. It was intriguing that $\mathrm{Mr}$. S attempted to position Simón as an expert who could explain his thinking to the class, but Simón appeared to resist this positioning (Table 5, lines 4 and 8). Simón's reticence contrasted with Damariz asking to explain her method (Table 4 line 18).

\section{Discussion}

This design research project sought to create classroom learning environments in which linguistically diverse ninth graders develop the dimensions of ALM through engaging in mathematical discussions (Moschkovich, 2015; Moschkovich \& Zahner, 2018). The findings presented here show it is possible to transform the patterns of classroom discourse in multilingual secondary mathematics classrooms. Additionally, the design principles and products of this design effort provide guidance for future research and development efforts in linguistically diverse secondary mathematics classrooms. In the following two sections, we summarize answers to the research questions that framed this work and then discuss limitations and future research directions.

\subsection{Design principles, classroom discussions, and ALM}

Explicitly answering RQ1, we see evidence that the lesson design features supported multilingual students' participation in classroom discussions. Specifically, in comparison with the traditional classroom discussions in Phase I, during Phases II and III, we saw a shift away from the IRE format of classroom talk as students engaged in mathematical practices (such as problem solving), while using more authentic mathematical discourse (such as explaining and justifying). These shifts in interaction can be traced to elements of this design effort. For example, the interaction in Table 4 was made possible by the lesson's conceptual focus (understanding linear rates of change), the mathematical practices embedded in the activity structure (problem solving), and the use of discourse supports (MLRs and dynamic technology).

Regarding RQ2, we note there was a reflexive relationship between student participation in mathematical discussions and their development of ALM. In particular, during the Phases II and III lessons, the qualitative analysis of excerpts of discussion showed how students engaged in mathematical practices and used mathematical discourse while developing proficiencies. While we are encouraged by the evidence of student engagement in ALM during this design effort, we also acknowledge that further research is needed to continue unpacking how the dimensions of ALM are interrelated and developed together in and through discussions. In a more controlled study, we might be able to isolate and measure these dimensions more precisely.

\subsection{Limitations and future research}

We note three limitations and suggest potential avenues for future research responsive to these limitations. First, 
we cannot claim there was a causal relationship between our redesign efforts and the changes in classroom discourse across Phases I, II, and III. Given the time lag between design iterations, changes in classroom interactions and $\mathrm{Mr}$. S's teaching practices may be attributable to factors beyond this design effort. To address this limitation, in future efforts, this work might be "scaled down" (O'Connor et al., 2015) to do smaller experimental tests of how specific variations of design features and teaching practices impact student learning. For example, future designs could investigate the effectiveness of MLRs by comparing a lesson that uses a specific MLR (e.g., Collect and Display) to a version of the same lesson that does not use that MLR. Such work may be critical for making research-based claims that certain design principles or instructional routines are "best practices." Also, such a detailed analysis might allow for further explication of how the dimensions of ALM are intertwined and developed together through participating in classroom discussions.

Second, the features of our redesigns were situated in and responsive to the local context of this research. This research was intentionally set in a large, comprehensive public school where the students and teachers in this school faced many of the systemic inequities that are common in US secondary schools serving English Learners (Gándara \& Contreras, 2009). Given the challenges presented by these systemic inequalities, it is important to note that the modest success of this project was supported by using research-grounded designs in the context of a long-term partnership between the research team and school personnel. The design principles and the unit/lesson designs that were created in this project may serve as a starting point for other researchers who seek to promote classroom discussions in multilingual settings. At the same time, translating the insights from this research into new settings with other teachers will likely require robust professional development frameworks (as in Herbel-Eisenmann et al., 2013) in addition to the project specific design principles. In future research, these principles can be tested and further refined in other multilingual secondary mathematics learning contexts.

Finally, this work, which has an overarching goal of increasing educational equity for multilingual learners, focused on redesigning the learning environment at the classroom level. Such classroom-level change does not address the larger systemic inequities that necessitate this research (Gándara \& Contreras, 2009). In the course of this research, we encountered multiple challenges from beyond the classroom walls including teacher turnover, yearly curriculum changes, and "accountability" pressures. While these challenges were beyond the scope of our control and the research intervention, they certainly shaped the enactment of our designs. Reflecting on the broader sociopolitical context of schooling for multilingual students in US secondary schools, in future work we hope to engage more teachers-and students, families, and community members-in co-designing secondary mathematics learning environments that may lead to a more humanizing vision of school mathematics (Gutiérrez, 2018). We also suggest that other redesign efforts that share the overarching goal of increasing educational equity for multilingual learners must necessarily engage with the broader school and social contexts and the systemic structures that create and maintain inequitable mathematics learning environments for multilingual students.

Acknowledgements This research was supported by a grant from the National Science Foundation (\#1553708) to William Zahner. Any opinions, findings, and conclusions or recommendations expressed in this material are those of the authors and do not necessarily reflect the views of The National Science Foundation. We acknowledge the assistance of Lynda Wynn, Yessika Gamala, and April Zuniga, and the collaboration of the teachers who are participating in this study.

Open Access This article is licensed under a Creative Commons Attribution 4.0 International License, which permits use, sharing, adaptation, distribution and reproduction in any medium or format, as long as you give appropriate credit to the original author(s) and the source, provide a link to the Creative Commons licence, and indicate if changes were made. The images or other third party material in this article are included in the article's Creative Commons licence, unless indicated otherwise in a credit line to the material. If material is not included in the article's Creative Commons licence and your intended use is not permitted by statutory regulation or exceeds the permitted use, you will need to obtain permission directly from the copyright holder. To view a copy of this licence, visit http://creativecommons.org/licenses/by/4.0/.

\section{References}

Barwell, R., Moschkovich, J.N., \& Phakeng, M. (2017). Language diversity and mathematics: Second language, bilingual, and multilingual learners. In J. Cai (Ed.), Compendium for research in mathematics education (pp. 583-606). National Council of Teachers of Mathematics

Callahan, R. M. (2005). Tracking and high school English learners: Limiting opportunity to learn. American Educational Research Journal, 42(2), 305-328.

Cazden, C. B. (2001). Classroom discourse: The language of teaching and learning (2nd ed.). Portsmouth: Heinemann.

National Governors Association Center for Best Practices \& Council of Chief State School Officers. (2010). Common core state standards for mathematics. Authors

Chapin, S., O’Connor, M., \& Anderson, N. (2009). Classroom discussions: Using math talk to help students learn (2nd ed.). Math Solutions

Chval, K. B., Pinnow, R. J., \& Thomas, A. (2014). Learning how to focus on language while teaching mathematics to English language learners: a case study of Courtney. Mathematics Education Research Journal, 27(1), 103-127.

Cobb, P., Confery, J., DiSessa, A., Lehrer, R., \& Schauble, L. (2003). Design experiments in educational research. Educational Researcher, 32, 9-13.

Cuoco, A., \& Kerins, B. (2013). Integrated CME project. London: Pearson. 
de Araujo, Z., Roberts, S. A., Willey, C., \& Zahner, W. (2018). English learners in K-12 mathematics education: a review of the literature. Review of Educational Research, 88(6), 879-919.

Erath, K., Prediger, S., Quasthoff, U., \& Heller, V. (2018). Discourse competence as important part of academic language proficiency in mathematics classrooms: the case of explaining to learn and learning to explain. Educational Studies in Mathematics, 99(2), $161-179$.

Erath, K., Ingram, J., Moschkovich, J.N., \& Prediger, S. (2021). Designing and enacting instruction that enhances language for mathematics learning - a review of the state of development and research. ZDM Mathematics Education, 53(2) (in this issue)

Forman, E. (1996). Learning mathematics as participation in classroom practice: Implications of sociocultural theory. In L. Steffe, P. Nesher, P. Cobb, G. A. Goldin, \& B. Greer (Eds.), Theories of mathematics learning (pp. 115-130). Mahwah: Lawrence Erlbaum.

Gándara, P. C., \& Contreras, F. (2009). The Latino education crisis: the consequences of failed social policies. Cambridge: Harvard University Press.

Gee, J. P., \& Green, J. L. (1998). Discourse analysis, learning, and social practice: A methodological study. Review of Research in Education, 23, 119-169.

Gutiérrez, R. (2002). Beyond essentialism: The complexity of language in teaching mathematics to Latina/o students. American Educational Research Journal, 39, 1047-1088.

Gutiérrez, R. (2018). Political conocimiento for teaching mathematics: Why teachers need it and how to develop it. In S. E. Kastberg, A. M. Tyminski, A. E. Lischka, \& W. B. Sanchez (Eds.), Building support for scholarly practices in mathematics methods (pp. 11-37). Charlotte: Information Age Publishing Inc.

Herbel-Eisenmann, B. A., Steele, M. D., \& Cirillo, M. (2013). (Developing) teacher discourse moves: a framework for professional development. Mathematics Teacher Educator, 1(2), 181-196.

Kanno, Y., \& Kangas, S. E. N. (2014). 'I'm not going to be, like, for the AP": English language learners' limited access to advanced college-preparatory courses in high school. American Educational Research Journal, 51(5), 848-878.

Lampert, M. (1990). When the problem is not the question and the solution is not the answer: Mathematical knowing and teaching. American Educational Research Journal, 27, 29-64.

Lobato, J., Ellis, A. B., \& Zibek, R. M. (2010). Developing essential understanding of ratios, proportions, and proportional reasoning for teaching mathematics: Grades 6-8. Reston: National Council of Teachers of Mathematics.

Miles, M. B., Huberman, A. M., \& Saldaña, J. (2014). Qualitative data analysis: A methods sourcebook. Philadelphia: SAGE.

Moschkovich, J. N. (1999). Supporting the participation of English language learners in mathematical discussions. For the Learning of Mathematics, 19, 11-19.

Moschkovich, J. N. (2002). A situated and sociocultural perspective on bilingual mathematics learners. Mathematical Thinking and Learning, 4, 189-212.

Moschkovich, J. N. (2007). Examining mathematical discourse practices. For the Learning of Mathematics, 27, 24-30.

Moschkovich, J. (2013). Principles and guidelines for equitable mathematics teaching practices and materials for English language learners. Journal of Urban Mathematics Education, 6(1), 45-57.

Moschkovich, J. N. (2015). Academic literacy in mathematics for English learners. The Journal of Mathematical Behavior, 40, 43-62.
Moschkovich, J. N., \& Zahner, W. (2018). Using the academic literacy in mathematics framework to uncover multiple aspects of activity during peer mathematical discussions. ZDM, 50(6), 999-1011.

National Research Council. (2001). Adding it up: Helping children learn mathematics. New York: National Academy Press.

O'Connor, M. C. (2001). "Can any fraction be turned into a decimal?": A case study of a mathematical group discussion. Educational Studies in Mathematics, 46, 143-185.

O'Connor, C., Michaels, S., \& Chapin, S. (2015). "Scaling down" to explore the role of talk in learning: From district intervention to controlled classroom study. In L. B. Resnick, C. S. C. Asterhan, \& S. N. Clarke (Eds.), Socializing intelligence through academic talk and dialogue (pp. 111-126). Washington: American Educational Research Association.

Pöhler, B., \& Prediger, S. (2015). Intertwining lexical and conceptual learning trajectories-A design research study on dual macroscaffolding towards percentages. EURASIA Journal of Mathematics, Science \& Technology Education, 11(6), 1697-1722.

Prediger, S., \& Zindel, C. (2017). School academic language demands for understanding functional relationships: A design research project on the role of language in reading and learning. Eurasia Journal of Mathematics, Science and Technology Education, 13(7b), 4157-4188.

Prediger, S., Gravemeijer, K., \& Confrey, J. (2015). Design research with a focus on learning processes: An overview on achievements and challenges. ZDM - Mathematics Education, 47(6), 877-891.

Schiffrin, D. (1994). Approaches to discourse. Oxford: Blackwell.

Thompson, P. W. (1994). The development of the concept of speed and its relationship to concepts of rate. In G. Harel \& J. Confrey (Eds.), The development of multiplicative reasoning in the learning of mathematics (pp. 179-234). Albany: SUNY Press.

Wertsch, J. V. (1991). Voices of the mind: A sociocultural approach to mediated action. Cambridge: Harvard University Press.

Wylie, C., Bauer, M., Bailey, A., \& Heritage, M. (2018). Formative assessment of mathematics and language: Applying companion learning progressions to reveal greater insights to teachers. In A. Bailey, C. A. Maher, \& L. C. Wilkinson (Eds.), Language, literacy, and learning in the STEM disciplines: How language counts for English Learners (pp. 143-168). London: Routledge.

Zahner, W., Velazquez, G., Moschkovich, J. N., Vahey, P., \& LaraMeloy, T. (2012). Mathematics teaching practices with technology that support conceptual understanding for Latino/a students. Journal of Mathematical Behavior, 31, 431-446.

Zahner, W., Pelaez, K., \& Calleros, E. (2020). Designing mathematics learning environments for multilingual students: Results of a redesign effort in introductory algebra. In A.I. Sacristán, J.C Cortés (Eds). Proceedings of the 42nd Annual Meeting of the North American Chapter of the International Group for the Psychology of Mathematics Education. PMENA, Mazatlán

Zwiers, J., Dieckmann, J., Rutherford-Quach, S., Daro, V., Skarin, R., Weiss, S., \& Malamut, J. (2017). Principles for the design of mathematics curricula: Promoting language and content development. Stanford University UL/Scale. http://ell.stanford.edu/conte $\mathrm{nt} /$ mathematics-resources-additional-resources

Publisher's Note Springer Nature remains neutral with regard to jurisdictional claims in published maps and institutional affiliations. 